\title{
O que podemos fazer pelo conhecimento em saúde?
}

A REEUSP completou mais um ano de produção. 2004 foi um ano de marcos importantes para a Universidade de São Paulo e para a Escola de Enfermagem. A Universidade completou 70 anos, a sua Pós-Graduação 35 anos e, na Escola de Enfermagem, a Pós-Graduação comemorou 30 anos. Nesta longa trajetória de uma renomada instituição pública de ensino superior, a REEUSP há 36 anos vem testemunhando o crescimento e o surgimento de novas gerações de pesquisadores em Enfermagem que muito tem contribuído para a maturidade acadêmica alcançada pela USP.

Como é próprio de cada ciclo que termina, ao final do ano fazemos um balanço do trabalho realizado e assim avaliamos os resultados obtidos frente às nossas metas. Diante de tantas celebrações podemos comemorar também o êxito de REEUSP frente às metas para 2004.

O êxito da revista deveu-se, sobretudo, ao resultado do trabalho de muitas pessoas. A liderança e orientação do editor, as sugestões de aprimoramento continuado do Conselho de Editores, o trabalho e a disponibilidade da Equipe Técnica e a colaboração inestimável dos pareceristas pelo tempo dedicado à análise cuidadosa de todos os manuscritos que recebemos.

Duas metas devem ainda continuar sendo nosso foco de atenção na contínua busca da excelência e da capacidade para gerar impacto sobre o conhecimento em saúde: a divulgação de conhecimento de qualidade e a internacionalização.

Em nosso compromisso com a qualidade, muitas vezes ajudamos alguns autores, não apenas revendo cuidadosamente o manuscrito, mas também oferecendo sugestões visando um produto final de qualidade para nossos leitores. É necessário reconhecer que este processo pode demandar revisões sucessivas para atingir uma apresentação aceitável ao padrão dos nossos leitores e dos autores que contribuem com a revista.

Quanto à internacionalização, sabemos que existe um rico conhecimento de Enfermagem e de outras áreas da saúde sendo produzido no mundo, que pode contribuir para os profissionais que trabalham em saúde. Nós queremos que a REEUSP seja reconhecida como um veículo de divulgação internacional também fora do Brasil. Por isso encorajamos os leitores e autores de língua inglesa e espanhola a submeterem seus trabalhos para publicação em nossa revista.

Quanto mais manuscritos recebermos, melhor selecionaremos para publicação aqueles que contém conhecimentos e evidências relevantes para a Enfermagem e a saúde em geral.

Assim, ao nos preparamos para um novo ciclo de trabalho, aproveitamos para despertar nos leitores e autores que ainda não colaboraram com a REEUSP o interesse em nos enviar seus manuscritos. "Onde estão vocês?” Nós estamos aqui, aguardando para publicar a sua contribuição para o conhecimento em saúde.

Este número traz a identificação das ações de Enfermagem que podem ser utilizadas por enfermeiros, no cuidado de pacientes com aids, a partir do Projeto de Classificação Internacional das Práticas de Enfermagem em Saúde Coletiva - CIPESC; um estudo prospectivo realizado em dois hospitais de ensino quanto a incidência de infecção do sítio cirúrgico no período intrahospitalar e pós-alta; a experiência de utilização das essências florais junto à 30 sujeitos num consultório na cidade de São Paulo e o relato pela história oral, de familiares sobre o convívio com o paciente psiquiátrico.

Os artigos referentes a aspectos da equipe de Enfermagem e de saúde são os que abordam os principais riscos ocupacionais a que estão expostos os trabalhadores de Enfermagem de uma UTI, os aspectos cronobiológicos do ciclo vigília-sono e níveis de ansiedade dos enfermeiros nos diferentes turnos de trabalho, as representações de uma equipe de saúde acerca do 
planejamento familiar e esterilização feminina e como se dá a produção da subjetividade dentro dos novos serviços de saúde mental utilizando como referencial teórico-metodológico uma abordagem chamada Sociopoética.

Concluindo a n.4/2004 temos a avaliação de alunos e professores acerca de um software sobre sinais vitais, uma revisão de literatura sobre a sexualidade, saúde reprodutiva e violência contra a mulher negra, os relatos de experiência profissional sobre a estruturação e desenvolvimento do Programa de Pós-Graduação em Enfermagem na Saúde do Adulto da EEUSP e sobre a educação de Enfermagem a distância, na experiência de utilização de ambiente on-line de aprendizagem na graduação de Enfermagem, num curso de Terapia Intensiva.

Novamente com a chegada de um "outro" dezembro percebemos que o tempo (chronos) está passando. O tempo das batidas do relógio marca a temporalidade humana e nossos limites, pois nos sentimos facilmente vítimas dele. Desejamos porém, a todos os leitores, consultores, os que contribuíram com a REEUSP, que o tempo kairós - o tempo como experiência da graça maior que plenifica a vida e dá sentido à ela, tenha prevalecido em 2004, tornando a chegada de 2005, um momento de expectativas e esperanças.

Feliz 2005!

Prof. ${ }^{a}$ Dr. ${ }^{a}$ Ana Maria Kazue Miyadahira Editora
Prof. ${ }^{a}$ Dr. ${ }^{a}$ Margareth Ângelo

Membro do Conselho de Editores

Prof. ${ }^{a}$ Dr. ${ }^{a}$ Maria Júlia Paes da Silva

Presidente do Conselho de Editores 